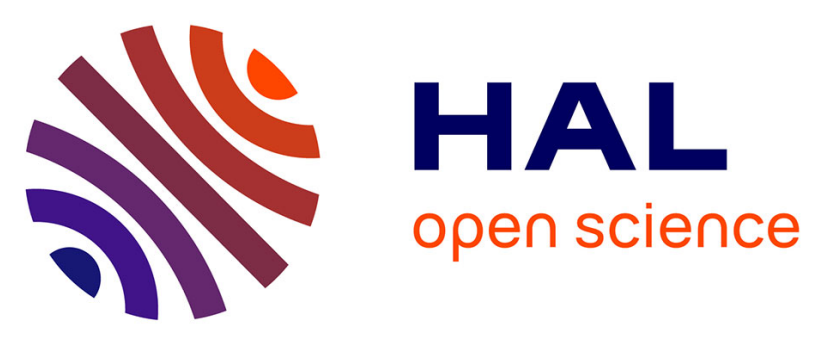

\title{
Visible Light Chiral Photoinitiator for Radical Polymerization and Synthesis of Polymeric Films with Strong Chiroptical Activity
}

A. Al Mousawi, M. Schmitt, F. Dumur, J. Ouyang, L. Favereau, V. Dorcet, N. Vanthuyne, P. Garra, J. Toufaily, T. Hamieh, et al.

\section{To cite this version:}

A. Al Mousawi, M. Schmitt, F. Dumur, J. Ouyang, L. Favereau, et al.. Visible Light Chiral Photoinitiator for Radical Polymerization and Synthesis of Polymeric Films with Strong Chiroptical Activity. Macromolecules, 2018, 51 (15), pp.5628-5637. 10.1021/acs.macromol.8b01085 . hal-01874726

HAL Id: hal-01874726

https://hal-univ-rennes1.archives-ouvertes.fr/hal-01874726

Submitted on 8 Apr 2019

HAL is a multi-disciplinary open access archive for the deposit and dissemination of scientific research documents, whether they are published or not. The documents may come from teaching and research institutions in France or abroad, or from public or private research centers.
L'archive ouverte pluridisciplinaire HAL, est destinée au dépôt et à la diffusion de documents scientifiques de niveau recherche, publiés ou non, émanant des établissements d'enseignement et de recherche français ou étrangers, des laboratoires publics ou privés. 


\title{
Visible Light Chiral Photoinitiator for Radical Polymerization and Synthesis of Polymeric Films with Strong Chiroptical Activity
}

\author{
Assi Al Mousawi, ${ }^{\dagger,}$ Michael Schmitt, ${ }^{\dagger}$ Frederic Dumur, ${ }^{*},{ }^{\S} \odot$ Jiangkun Ouyang, ${ }^{\perp}$ Ludovic Favereau, ${ }^{\perp}$ \\ Vincent Dorcet, ${ }^{\perp}$ Nicolas Vanthuyne, ${ }^{\|}$Patxi Garra, ${ }^{\dagger}$ Joumana Toufaily, ${ }^{\ddagger}$ Tayssir Hamieh, ${ }^{\ddagger}$ \\ Bernadette Graff, ${ }^{\dagger}$ Jean Pierre Fouassier, ${ }^{\dagger}$ Didier Gigmes, ${ }^{\S}$ Jeanne Crassous, ${ }^{*, \perp}{ }_{\odot}$ \\ and Jacques Lalevée* ${ }^{*} \dagger$ (1)
}

\footnotetext{
${ }^{\dagger}$ Institut de Science des Matériaux de Mulhouse IS2M - UMR CNRS 7361, UHA, 15, rue Jean Starcky, Cedex 68057 Mulhouse, France

${ }^{\ddagger}$ Laboratoire de Matériaux, Catalyse, Environnement et Méthodes analytiques (MCEMA-CHAMSI), EDST, Université Libanaise, Campus Hariri, Hadath, Beyrouth, Liban

${ }^{\S}$ Aix Marseille Univ, CNRS, ICR UMR 7273, 13397 Marseille, France

"Aix Marseille Univ, CNRS, Centrale Marseille, iSm2, UMR 7313, 13397 Marseille, France

${ }^{\perp}$ Institut des Sciences Chimiques de Rennes UMR 6226, CNRS Univ Rennes, Campus de Beaulieu, Cedex 35042 Rennes, France
}

ABSTRACT: 3-Methyl-4-aza[6]helicene (A6H) enantiomers were synthesized and proposed as high-performance visible light photoinitiators and/or photosensitizers for the free radical polymerization (FRP) of (meth)acrylates upon visible light exposure using inexpensive and safe light-emitting diodes (LEDs) at $405 \mathrm{~nm}$. Excellent polymerization initiating abilities were found, and high final conversions were obtained. Remarkably, an exceptional strongly enhanced chiral property

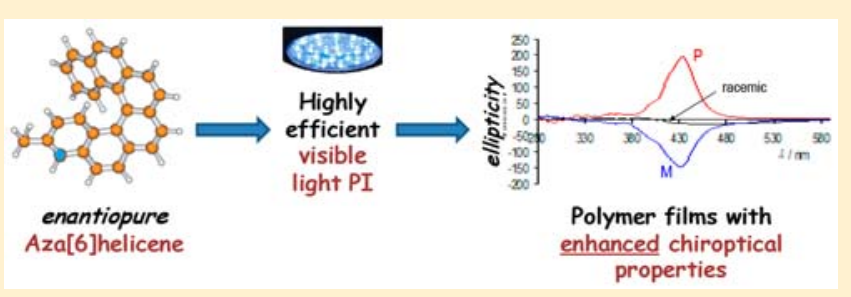
of the polymer films was observed in the presence of the enantiopure azahelicenes. This is the first example of chiral properties introduced in polymer films by the photoinitiator through photopolymerization processes. It is of high interest as these latter are very fast and inexpensive polymerization techniques. Remarkably, contrary to chiral properties introduced by using a combination of commercial photoinitiator and chiral dopant, a dual behavior is found here for $\mathrm{A} 6 \mathrm{H}$. A full picture of the involved chemical mechanisms is given.

\section{INTRODUCTION}

Helical structure is a ubiquitous structural feature widespread in our daily life and microscopic world. ${ }^{1}$ In chemistry, helicenes ${ }^{2-7}$ are the archetype of polycyclic aromatic hydrocarbons (PAHs) with nonplanar screw-shaped structures composed of ortho-fused aromatic rings. The natural springlike helical shape of such structures can be ascribed to the impotence of fused rings to occupy the same plane. ${ }^{8,9}$ On the basis of its springlike composition, the solubility of helicenes is typically much higher than that of planar polycyclic aromatic hydrocarbons (PAH) due to the decrease of $\pi-\pi$ stacking interactions in the former molecules. ${ }^{10}$ Azahelicenes are a class of helicenes bearing at least one nitrogen heteroatom characterized by (i) intense absorption properties in the near-UV and visible light, (ii) strong luminescence properties, and (iii) good redox properties. These properties allow azahelicenes to serve as good candidates in photoinitiating systems (PISs) for polymer frameworks. ${ }^{11}$ Other essential features are also due to their helical structure. Aza[6] helicenes are configurationally stable chiral compounds and can exist as right-handed and left-handed enantiomeric forms. Their helical structure, in combination with their $\pi$-conjugated structure, provide these molecules with strong chiroptical properties, including intense circular dichroism (CD) spectra. ${ }^{2,3}$

In a previous work, azahelicenes incorporating a carbazole unit were used as visible light photoinitiating systems for both cationic and radical polymerizations. Interestingly, they were outlined for the first time as (metal-free) polymer films with exceptionally long (e.g., $1.1 \mathrm{~s}$ ) photoluminescence lifetimes. ${ }^{11}$ However, in that former work, the chiral properties of the azahelicene molecules as well as those of the produced polymer films were not considered. More precisely, the previous helicenic derivatives were not configurationally stable and impeded the investigation of this aspect. In the literature, chiral properties were only introduced by photopolymerization using a combination of commercial photoinitiator and chiral dopant. $^{12-14}$ Therefore, there is a need for new highly efficient 
PISs coupling chiroptical properties in the final photopolymer for high-tech applications.

In this work, we selected both right-handed $(P)$ and lefthanded $(M)$ 3-methyl-4-aza[6]helicene $(\mathrm{A} 6 \mathrm{H})$ and the corresponding racemic mixture (Scheme 1 ) to investigate (i)

Scheme 1. Synthetic Scheme of the Investigated 3-Methyl-4aza[6] helicene $(\mathrm{A6H})$ in Its Different Forms ${ }^{a}$

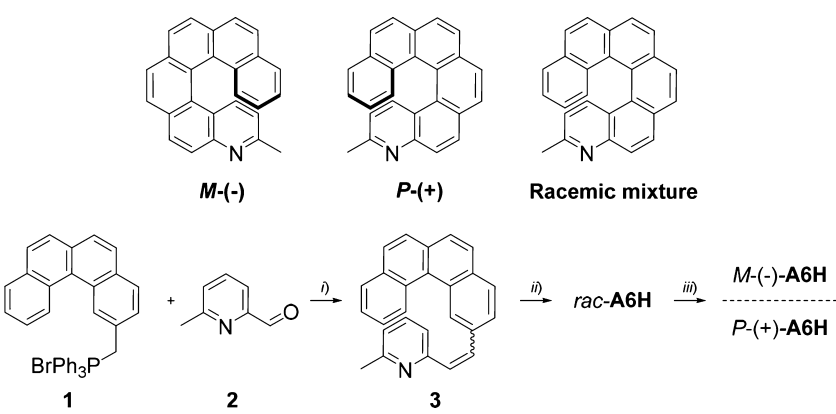

${ }^{a}$ Reagents and conditions: (i) $n$-BuLi, THF, rt, 3 h, $84 \%$; (ii) $h \nu$, cat. $\mathrm{I}_{2}$, toluene, $7 \mathrm{~h}, 63 \%$; (iii) HPLC separation over a chiral stationary phase (see also in the Supporting Information).

its ability to initiate free radical polymerization (FRP) process under visible light delivered by actinic LEDs, e.g., at $405 \mathrm{~nm}$, and (ii) chiroptical properties of the formed polymer. The absorption properties, luminescence properties, and electrochemical properties of azahelicenes were also studied. First of all, the chiroptical response of the enantiomerically pure azahelicenes in solution will be illustrated by circular dichroism measurements. In addition, their photoinitiating ability could be highly worthwhile to synthesize strongly chiral polymeric films. Therefore, we will show whether chirality-related properties can be introduced in polymer films by the photoinitiator through fast ( $<20 \mathrm{~s}$ of irradiation) and cheap (using LED@405 nm) photopolymerization processes. The originality in our work is the dual behavior of $\mathrm{A} 6 \mathrm{H}$ which plays both roles. These properties will be discussed in detail as we will show that the chiral features of the photoinitiator might be transferred (or embedded) to the polymer matrix. For example, this inexpensive chiral polymer synthesis using this new photoinitiating system may induce a high chiral recognition of various racemic compounds especially for chiral packing material (CPM) for HPLC. ${ }^{13,14}$

\section{EXPERIMENTAL PART}

Chemical Compounds. N-tert-Butyl- $\alpha$-phenyl nitrone (PBN), dibenzoyl peroxide (BPO), 4- $N, N$-trimethylaniline (4-N,N-TMA), and ethyl 4-(dimethylamino)benzoate (EDB) were obtained from Sigma-Aldrich (Figure 1). Bis(4-tert-butylphenyl)iodonium hexafluorophosphate (Iod or Speedcure 938) and bis(2,4,6-trimethylbenzoyl)phenylphosphine oxide (BAPO) were obtained from Lambson Ltd. (Figure 1). Trimethylolpropane triacrylate (TMPTA, Figure 2) was obtained from Allnex, and bisphenol A-glycidyl methacrylate (BisGMA) and triethylene glycol dimethacrylate (TEGDMA) were purchased from Sigma-Aldrich and used as benchmark monomers for radical photopolymerization with the highest purity available. The synthesis procedure of the different 3-methyl-4-aza[6]helicene $(\mathrm{A} 6 \mathrm{H})$ enantiomers is described in the Supporting Information.

Irradiation Sources. The following light-emitting diode (LED) was used as irradiation source: LED@405 nm; the incident light intensity at the sample surface is $I_{0} \approx 110 \mathrm{~mW} \mathrm{~cm}^{-2}$.

Computational Procedure. Molecular orbital calculations were carried out with the Gaussian 03 suite of programs. ${ }^{15,16}$ The electronic

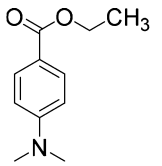

EDB<smiles>CC(C)(C)[N+](=O)Cc1ccccc1</smiles>

PBN

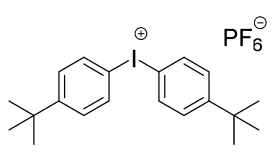

$\operatorname{lod}$

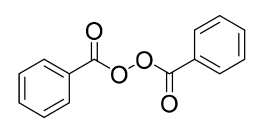

BPO

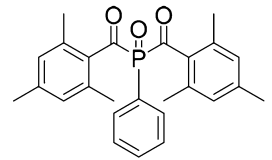

BAPO
Figure 1. Used chemical compounds.

absorption spectra for the different compounds were calculated with the time-dependent density functional theory at the B3LYP/6-31G* level of theory on the relaxed geometries calculated at the UB3LYP/6$31 \mathrm{G}^{*}$ level of theory.

Free Radical (FRP) Photopolymerization. The two-component photoinitiating systems are mainly based on a mixture of $0.1 \%-0.5 \%$ $\mathrm{w} / \mathrm{w}$ of $\mathrm{A} 6 \mathrm{H}$ and $1.0 \% \mathrm{w} / \mathrm{w}$ of the iodonium salt $(\mathrm{A} 6 \mathrm{H} /$ iodonium salt $=0.1 \%-0.5 \% / 1.0 \% \mathrm{w} / \mathrm{w})$. The weight percent of the photoinitiating system is calculated from the monomer content. The photosensitive formulations $\sim 25 \mu \mathrm{m}$ and $1.4 \mathrm{~mm}$ thick were deposited on a $\mathrm{BaF}_{2}$ pellet in laminate or under air, respectively. The evolution of the acrylate or methacrylate double bond content was continuously followed by real-time FTIR spectroscopy (JASCO FTIR 4100) at about $1620 \mathrm{~cm}^{-1}$ for thin films $\sim 25 \mu \mathrm{m}$ and at about $6160 \mathrm{~cm}^{-1}$ for $1.4 \mathrm{~mm}$ thick ones. ${ }^{17}$

Free Energy Calculations. The free energy change $\Delta G_{\text {et }}$ for an electron transfer reaction was calculated from the classical equation (eq 1$)^{18}$ where $E_{\mathrm{ox}}, E_{\mathrm{red}}, E_{\mathcal{S}}$, and $C$ are the oxidation potential of the electron donor, the reduction potential of the electron acceptor, the excited state energy, and the Coulombic term for the initially formed ion pair, respectively. $C$ is neglected as usually done in polar solvents.

$$
\Delta G_{\text {et }}=E_{\text {ox }}-E_{\text {red }}-E_{\mathrm{S}}+C
$$

ESR Spin Trapping (ESR-ST) Experiments. The ESR-ST experiments were carried out using an X-band spectrometer (Bruker EMX-Plus). LED@405 nm was used as the irradiation source for triggering the production of radicals at room temperature (RT) under $\mathrm{N}_{2}$-saturated toluene/dichloromethane $(90 / 10)$ and trapped by phenyl- $N$-tert-butyl nitrone (PBN) according to a procedure described elsewhere in detail. ${ }^{19}$ The ESR spectra simulations were carried out with the PEST WINSIM program.

Absorption Experiments. The absorbance properties of the compounds were studied using a JASCO V730 UV-vis spectrometer.

Fluorescence Experiments. The fluorescence properties of the compounds were studied using a JASCO FP-6200 spectrometer.

Circular Dichroism and Ellipticity Measurements. Circular dichroism spectra (in $\mathrm{M}^{-1} \mathrm{~cm}^{-1}$ ) were measured on a Jasco J-815 circular dichroism spectrometer (IFR140 facility - Biosit; University of Rennes 1).

Trapping 3-Methyl-4-aza[6]helicene Enantiomers in a Polymer Network through Redox Polymerization. All redox formulations were prepared from the bulk resins in two separate cartridges: a first cartridge with dibenzoyl peroxide (BPO, Aldrich) and the other one containing the helicene (and 4- N,N-trimethylaniline, i.e., 4-N,N-TMA) (Figure 1). A 1:1 Sulzer mixpac mixer was used to mix both components together at the beginning of each polymerization experiment (about $1.4 \mathrm{~mm}$ thick). The contents of the chemical compounds were calculated in weight with respect to the resin in the final mixture. All polymerization experiments will be carried out under mild conditions: room temperature (RT) (21-23 ${ }^{\circ} \mathrm{C}$ ) and under air. Corresponding RT-FTIR Kinetics will be given in the Supporting Information. 
<smiles>C=C(C)C(=O)OCC(O)COc1ccc(C(C)(C)c2ccc(OCC(O)COC(=O)C(=C)C)cc2)cc1</smiles>

BisGMA
$\mathrm{CH}_{\mathrm{CH}_{3}}^{\mathrm{O}} \overbrace{\mathrm{O}}^{\mathrm{O}} \overbrace{\mathrm{OH}_{2}}^{\mathrm{CH}_{3}}$

TEGDMA<smiles>C=CC(=O)OCC(CC)(COC(=O)C=C)COC(=O)C=C</smiles>

TMPTA<smiles>C=C(C)C(=O)OCCO</smiles>

HEMA

Figure 2. Benchmark monomers used.

(A)

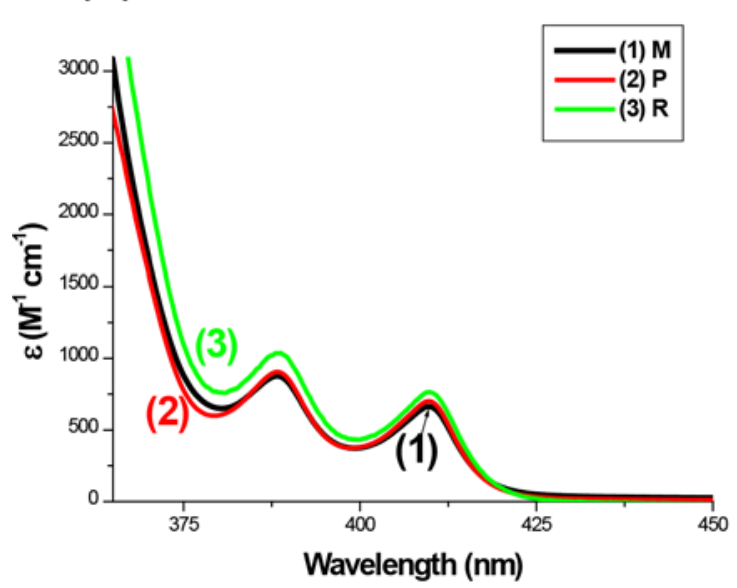

(B)

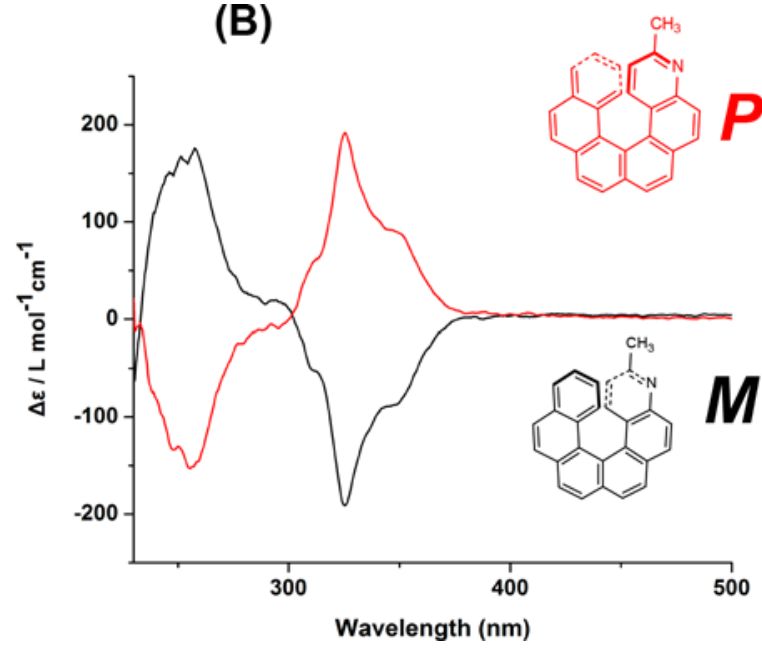

Figure 3. (A) Absorption spectra of the A6H investigated compounds in acetonitrile in its different forms: (1) M; (2) $P$; (3) racemic mixture. (B) Circular dichroism of $M-(-)$ and $P-(+)-\mathrm{A} 6 \mathrm{H}$ enantiomers $\left(\mathrm{CH}_{2} \mathrm{Cl}_{2}, \mathrm{C}=5 \times 10^{-5} \mathrm{M}\right)$.

Photolysis Product Analysis with High-Resolution Electrospray lonization-Mass Spectrometry (HR-ESI-MS). Photolysis was performed using a LED@405 nm for $3 \mathrm{~min}$. Two solutions were prepared: a first DCM solution of $100 \mathrm{~g} / \mathrm{L}$ (racemic) helicene with 1 equiv of iodonium salt and then the same solution with 1 equiv of 2 hydroxyethyl methacrylate (HEMA, Aldrich) (Figure 2). A low stoichiometry of monomer was chosen in order to avoid the production of polymers with too high molecular weight.

Subsequent HR-ESI-MS was performed using an SYNAPT G2 HDMS (Waters). The two solutions in dichloromethane were diluted at $1 / 10$ in a methanol solution containing $3 \mathrm{mM}$ ammonium acetate. They were subsequently introduced in the ionization source at a flow rate of $10 \mu \mathrm{L} / \mathrm{min}$. Commercial poly(ethylene glycol) (PEG400) was used as an internal standard.

\section{RESULTS AND DISCUSSION}

Synthesis of 3-Methyl-4-aza[6]helicene (A6H) Enantiomers. Compound $\mathrm{A} 6 \mathrm{H}$ was prepared in good yield using the classical Wittig reaction-photocyclization sequence, as described in Scheme 1. The new helicene derivative was obtained in its racemic form, and subsequent HPLC separation over a chiral stationary phase (see the Supporting Information) afforded both $P$ and $M$ enantiomer with $e e$ 's higher than $98.5 \%$.

Properties of 3-Methyl-4-aza[6]helicene Enantiomers. Light Absorption Properties and Chiroptical Properties. The absorption spectra of the newly proposed photoinitiators in acetonitrile are reported in Figure 3. These compounds are characterized by excellent extinction coef- ficients in not only the near-UV but also the visible range; e.g., all of the three forms are characterized by two maxima peaks: the first peak at near-UV $\left(\varepsilon \sim 850 \mathrm{M}^{-1} \mathrm{~cm}^{-1}\right.$ at $\lambda_{\max 1} \sim 388$ $\mathrm{nm})$ and the second peak at visible region $\left(\varepsilon \sim 700 \mathrm{M}^{-1} \mathrm{~cm}^{-1}\right.$ at $\lambda_{\max 2} \sim 409 \mathrm{~nm}$ ) (Table 1). Remarkably, their absorptions

Table 1. Molar Extinction Coefficients for Ground State Absorption $\varepsilon$, Singlet Excited State Energies $E_{S 1}$, Oxidation Potentials $E_{\mathrm{ox}}$, Reduction Potentials $E_{\text {red }}$, and Fluorescence Lifetime $\tau$

\begin{tabular}{cccccc}
$\mathrm{A} 6 \mathrm{H}$ & $\begin{array}{c}\varepsilon \text { in }\left[\mathrm{M}^{-1} \mathrm{~cm}^{-1}\right] \\
\text { at } 405 \mathrm{~nm}\end{array}$ & $E_{\mathrm{S} 1}[\mathrm{eV}]$ & $\begin{array}{c}E_{\text {ox }} \mathrm{vs} \\
\text { SCE }[\mathrm{V}]\end{array}$ & $\begin{array}{c}E_{\text {red }} \mathrm{vs} \\
\mathrm{SCE}[\mathrm{V}]\end{array}$ & $\begin{array}{c}\tau^{\mathrm{A}}[\mathrm{ns}] \\
\text { (under } \mathrm{N}_{2} \text { ) }\end{array}$ \\
$P$ & $\sim 500$ & 3 & 1.4 & -1.9 & 17.3 \\
$M$ & $\sim 500$ & 3 & 1.4 & -1.9 & \\
\hline
\end{tabular}

are excellent in the $350-450 \mathrm{~nm}$ spectral range ensuring good matching with the emission spectrum of the LED used in this work (at $405 \mathrm{~nm}$ ). In comparison with other studied azahelicenes, $^{11}$ e.g., AZ2 and AZ3 with three phenyl orthocondensed aromatic rings in the helicene moiety (compared to five aromatic rings in the $\mathrm{A} 6 \mathrm{H}$ enantiomers), a bathochromic shift of $\sim 25 \mathrm{~nm}$ is found. This is mainly due to the extension of the $\pi$-system which usually plays a crucial role in the associated light absorption properties.

The optimized geometries, as well as the computed frontier orbitals (highest occupied molecular orbital, HOMO, and 


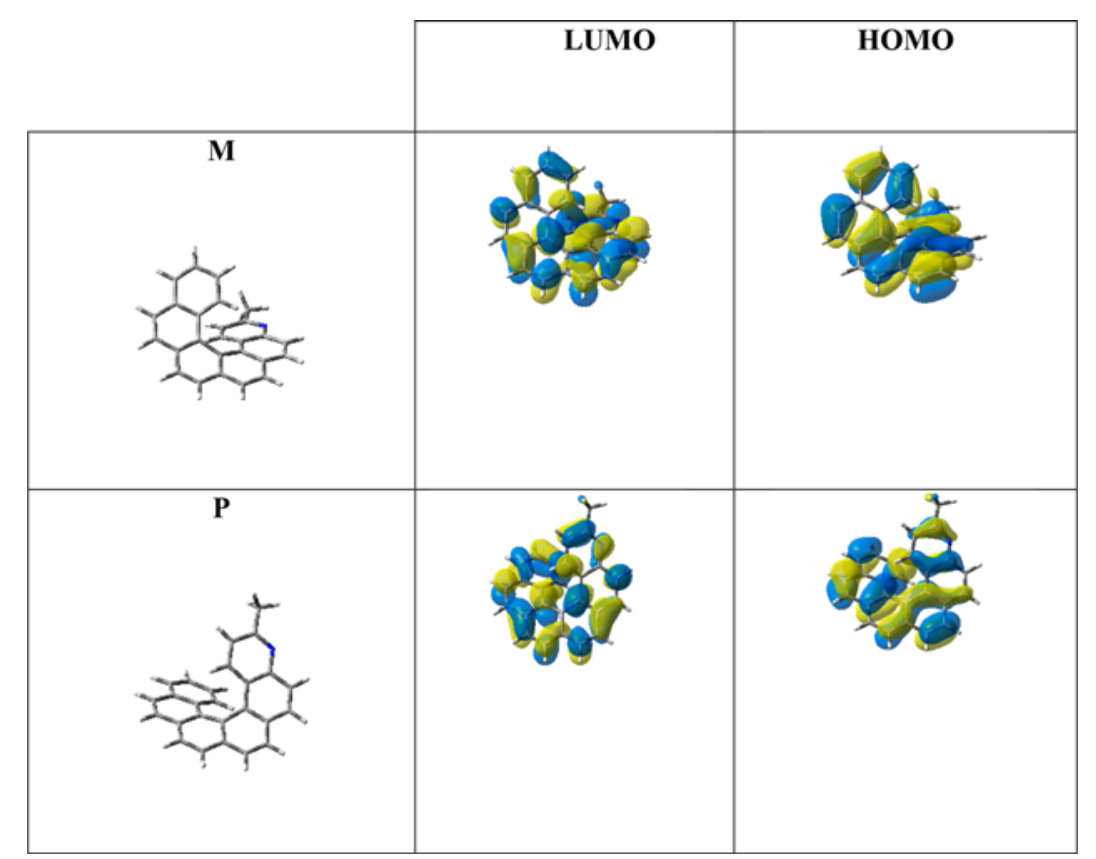

Figure 4. Contour plots of HOMOs and LUMOs for both enantiomers optimized at the B3LYP/6-31G* level of theory.
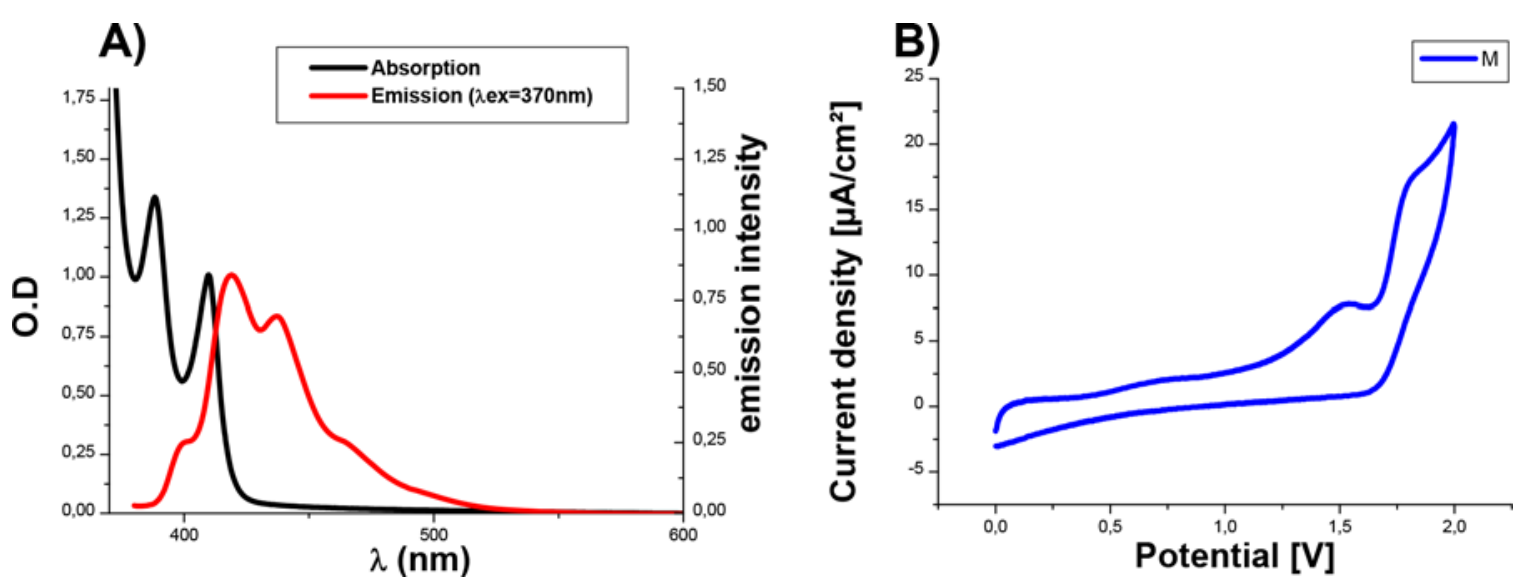

Figure 5. (A) Absorption and fluorescence spectra for the determination of the excited singlet state energy. (B) Cyclic voltammetry (CV, potential vs SCE) experiments in DCM (containing $0.2 \mathrm{M}$ tetrabutylammonium hexafluorophosphate) for the oxidation process of $M$.

lowest unoccupied molecular orbital, LUMO), are shown in Figure 4. Both the HOMO and LUMO are strongly delocalized all over the $\pi$ system showing a $\pi \rightarrow \pi^{*}$ transition.

As far as chiroptical properties are concerned, $P$ - and $M$ A6H show the expected opposite-sign specific rotation values (for instance, for the P-enantiomer: $[\alpha]_{\mathrm{D}}^{23}=+3190^{\circ}[\mathrm{dm}(\mathrm{g}$ $\left.\left.\mathrm{cm}^{-3}\right)\right]^{-1}$ in $\left.\mathrm{CH}_{2} \mathrm{Cl}_{2}, \mathrm{C}=5 \times 10^{-5} \mathrm{M}\right)$ and mirror-image ECD spectra (Figure $3 \mathrm{~B}$ ). The experimental ECD of $\mathrm{P}$-A6H displays one intense negative band at $257 \mathrm{~nm}\left(\Delta \varepsilon=-152 \mathrm{M}^{-1} \mathrm{~cm}^{-1}\right)$ and one intense positive band at $325 \mathrm{~nm}\left(\Delta \varepsilon=+195 \mathrm{M}^{-1}\right.$ $\mathrm{cm}^{-1}$ ). Both bands display some structuration probably due to vibronic progression. This CD signature is typical of organic helicenes and enables to assign the $M-(-)$ and $P-(+)$ absolute configurations. ${ }^{2,3}$

Photophysical and Electrochemical Properties. The enantiomeric forms of a chiral molecule display indistinguishable physical and chemical properties but are affected differently by a circularly polarized light, and they interact differently with other chiral molecules. The oxidation and reduction potentials, $E_{\text {ox }}$ and $E_{\text {red, }}$ respectively, of $\mathrm{A} 6 \mathrm{H}$ enantiomers were assessed in acetonitrile by cyclic voltammetry using the supporting electrolyte tetrabutylammonium hexafluorophosphate $(0.1 \mathrm{M})$. Both enantiomers were found to have roughly the same reduction and oxidation values as expected, e.g., $E_{\text {ox }}=1.4 \mathrm{~V}$ and $E_{\text {red }}=-1.9 \mathrm{~V}$ (Figure 5B and Table 1).

The excited state energies, evaluated from the crossing point of the absorption and fluorescence spectra (Table 1), are similar for both $\mathrm{A} 6 \mathrm{H}$ enantiomers $\sim 3 \mathrm{eV}$ (e.g., of $M$; Figure $5 \mathrm{~A})$ as well as the $\mathrm{A} 6 \mathrm{H}$ luminescence lifetimes $(\tau)$ determined using laser flash photolysis (LFP) experiments. In fact, the lifetimes measured are in the nanosecond range (e.g., $\tau_{\mathrm{P}}=17.3$ ns under $\mathrm{N}_{2}$; Table 1).

Free Radical Photopolymerization (FRP). $A 6 H$ as Visible Light Photoinitiator: Photopolymerization of Acrylates. $\mathrm{A} 6 \mathrm{H}(P$ or $M)$ enantiomers were tested as photosensitizers/photoinitiators in combination with a iodonium salt. In general, the $\mathrm{A} 6 \mathrm{H} / \mathrm{Iod}$ interaction inside the resin medium corresponds to an electron transfer reaction, finally leading to an aryl radical $\mathrm{Ar}^{\bullet}$ (reactions $\mathrm{r} 2$ ). $\mathrm{Ar}^{\bullet}$ is considered 


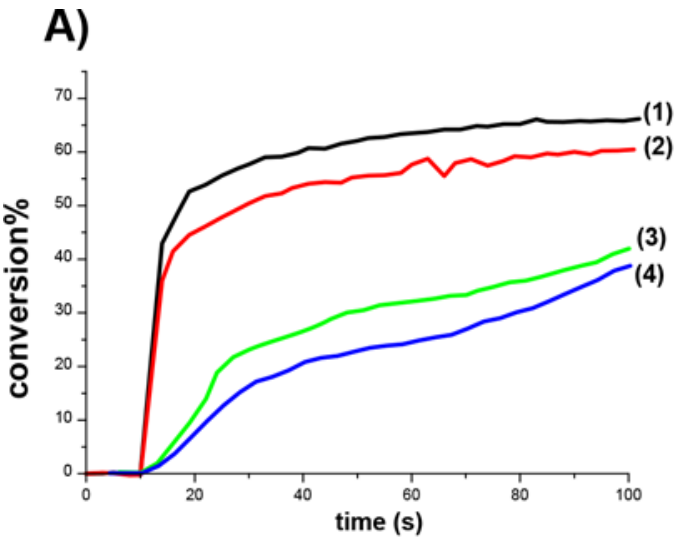

C)

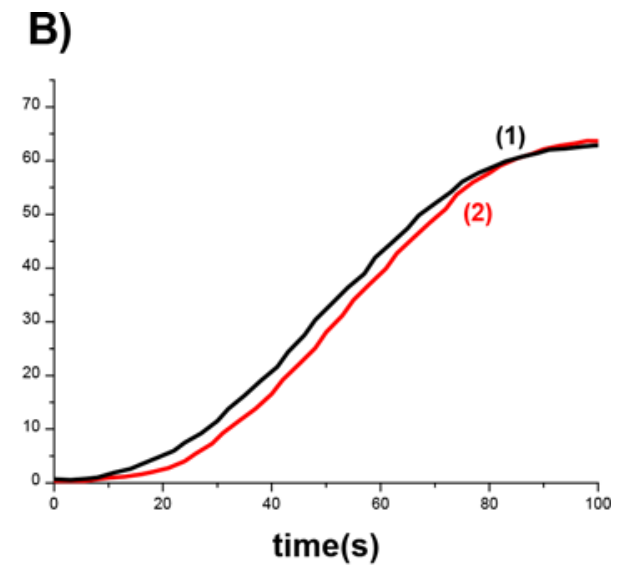

time(s)

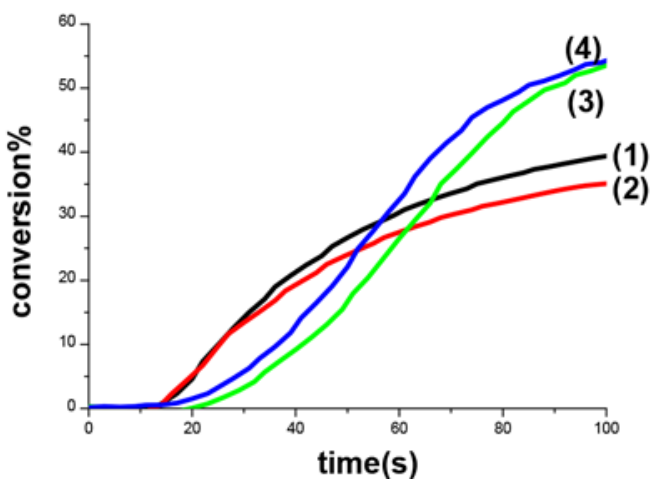

Figure 6. (A) Polymerization profiles (acrylate function conversion vs irradiation time) of TMPTA in the presence of the two-component photoinitiating systems A6H/Iod (0.5\%/1\% w/w) upon exposure to LED@405 nm: $25 \mu \mathrm{m}$ film thickness in laminate, curve (1) P/Iod and curve (2) $M /$ Iod; $1.4 \mathrm{~mm}$ sample thickness under air, curve (3) $P /$ Iod and curve (4) $M /$ Iod. (B) Polymerization profiles (methacrylate function conversion vs irradiation time) of BisGMA/TEGDMA under air in the presence of the two-component photoinitiating systems A6H/Iod (0.5\%/ $1 \%$ w/w) upon exposure to LED@405 nm: 1.4 mm thickness film curve (1) P/Iod and curve (2) M/Iod. (C) Polymerization profiles (acrylate function conversion vs irradiation time) of TMPTA in the presence of the two-component photoinitiating systems A6H/EDB $(0.5 \% / 1 \% \mathrm{w} / \mathrm{w})$ upon exposure to LED@405 nm: $25 \mu \mathrm{m}$ film thickness in laminate, curve (1) M/EDB and curve (2) P/EDB; 1.4 mm sample thickness under air, curve (3) $P$ /Iod and curve (4) $M$ /Iod.

as the initiating species for the radical polymerization, and this was confirmed by trapping $\mathrm{Ar}^{\bullet}$ in tert-butylbenzene solution using $N$-tert-butyl- $\alpha$-phenylnitrone PBN radical trap agent, as the $\mathrm{PBN} / \mathrm{Ar}$ adduct was observed from ESR results upon $\mathrm{A} 6 \mathrm{H} / \mathrm{Iod}$ interaction (see the Chemical Mechanisms section):

$$
\begin{aligned}
& \mathrm{A} 6 \mathrm{H}(h v) \rightarrow{ }^{1} \mathrm{~A} 6 \mathrm{H} \\
& { }^{1} \mathrm{~A} 6 \mathrm{H}+\mathrm{Ar}_{2} \mathrm{I}^{+} \rightarrow{\mathrm{A} 6 \mathrm{H}^{\bullet+}}^{\bullet} \mathrm{Ar}_{2} \mathrm{I}^{\bullet} \rightarrow{\mathrm{A} 6 \mathrm{H}^{\bullet+}}^{\circ} \mathrm{Ar}^{\bullet}+\mathrm{ArI}
\end{aligned}
$$

Photopolymerization of Acrylates: A6H/lod in TMPTA. Interestingly, the FRP of TMPTA in thin films $(25 \mu \mathrm{m}$ in laminate) in the presence of the different $\mathrm{A} 6 \mathrm{H} / \mathrm{Iod}$ couples is efficient using LED@405 nm, while Iod alone or A6H alone is not able to initiate the polymerization. High final acrylate function conversions (FCs) were obtained e.g. for P/Iod with $\mathrm{FC}=65 \%$ after only $100 \mathrm{~s}$ (Figure 6A, curve 1). High-level rates of polymerization accompany the high FCs (see Figure $6 \mathrm{~A}$ ), and no significant oxygen inhibition was noticed. However, for thicker films $(1.4 \mathrm{~mm})$, the efficiency of $\mathrm{A} 6 \mathrm{H}$ is considerably lower. This is well obvious in Figure 6A when comparing the behavior of $\mathrm{P} /$ Iod system for thin and thick films (e.g., $\mathrm{FC}=65 \%$ at $t=100 \mathrm{~s}$ for $25 \mu \mathrm{m} \gg \mathrm{FC} \sim 44 \%$ at $t$ $=100 \mathrm{~s}$ for $1.4 \mathrm{~mm}$ thickness; Figure $6 \mathrm{~A}$, curve 1 vs curve 3, respectively). The color of the final polymer obtained is a strong yellow color corresponding to $\mathrm{A} 6 \mathrm{H} / \mathrm{Iod}$ photoproduct formation. This might help to better understand the origin of the higher efficiency of $\mathrm{A} 6 \mathrm{H} / \mathrm{Iod}$ PIS in thinner samples. In detail, the inner filter effect corresponding to absorption of LED-emitted light by the surface of the top layer of $1.4 \mathrm{~mm}$ sample might inhibit the light penetration through the entire layers causing this deficiency in efficiency. To confirm this effect, the concentration of $\mathrm{A} 6 \mathrm{H}$ in thick samples is decreased to $0.25 \%$. This decrease in concentration allows higher FCs (e.g., $\mathrm{FC}=48 \%$ in $0.25 \% / 1 \% \mathrm{P} / \mathrm{Iod}$ vs $\mathrm{FC}=44 \%$ in $0.5 \% / 1 \%$ $\mathrm{P} /$ Iod for the same conditions $1.4 \mathrm{~mm}$ thickness).

In comparison with reference PIS such as BAPO/Iod (0.5\%/ $1 \% \mathrm{w} / \mathrm{w}), \mathrm{A} 6 \mathrm{H} / \mathrm{Iod}$ is better PISs in terms of efficiency and reactivity.

Photopolymerization of Methacrylates. Remarkably, A6H/Iod is an efficient PIS also for a blend of methacrylates (70/30) BisGMA/TEGDMA; i.e., high final conversions were obtained for both $\mathrm{P} / \mathrm{Iod}$ and $\mathrm{M} / \mathrm{Iod}$ PISs, thick samples (1.4 $\mathrm{mm}$ ) with a low content of photoinitiator $(0.1 \%)$. For example, FCs $\sim 63 \%$ at $t=100 \mathrm{~s}$ for both enantiomers when combined with Iod (Figure 6B, curves 1 and 2).

A6H/EDB as Visible Light Type II Photoinitiator. A6H (P and $M$ ) enantiomers were also tested as type II photoinitiators with an amine (EDB in Figure 1) to initiate acrylate FRP. Upon irradiation by LED@405 nm, a reaction is supposed to undergo between the singlet excited state of ${ }^{1} \mathrm{~A} 6 \mathrm{H}$ and the amine EDB. According to reactions $\mathrm{rl}$ and $\mathrm{r} 3 \mathrm{EDB}_{(-\mathrm{H})}$ is 
formed upon a photoreduction process in which an electron is transferred from EDB to $\mathrm{A} 6 \mathrm{H}$ in its excited state. Thus, $\mathrm{EDB}^{\bullet}{ }_{(-\mathrm{H})}$ can attack the double bond of acrylates and thereby initiate FRP. These reactions are fully compatible with the literature. $^{20}$

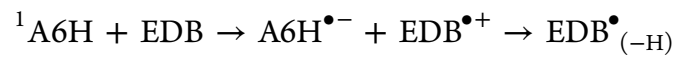

The FRP of TMPTA of both thin films $25 \mu \mathrm{m}$ (in laminate to avoid oxygen reaction with $\mathrm{EDB}^{{ }_{(-\mathrm{H})}}$ radicals) and thick films $1.4 \mathrm{~mm}$ (under air, as oxygen inhibition is less critical phenomenon in thick samples ${ }^{20}$ ) in the presence of the different $\mathrm{A} 6 \mathrm{H} / \mathrm{EDB}(0.5 \% / 1 \% \mathrm{w} / \mathrm{w})$ couples is efficient using LED@405 nm, while EDB alone or A6H alone cannot initiate FRP. This proves that $\mathrm{A} 6 \mathrm{H}$ is an efficient type II photoinitiator for thin samples. Typical acrylate function conversion-time profiles are depicted in Figure 6C, and the FCs are summarized in Table 2.

Table 2. Final Reactive Function Conversion (FC) for Acrylates in TMPTA Monomer and Methacrylates for BisGMA/TEGDMA Mixture (70/30), in Both Systems (1) A6H/Iod (0.1-0.5\%/1\%) and (2) A6H/EDB (0.1-0.5\%/ 1\%) upon LED@405 nm Irradiation (at $t=100 \mathrm{~s}$ )

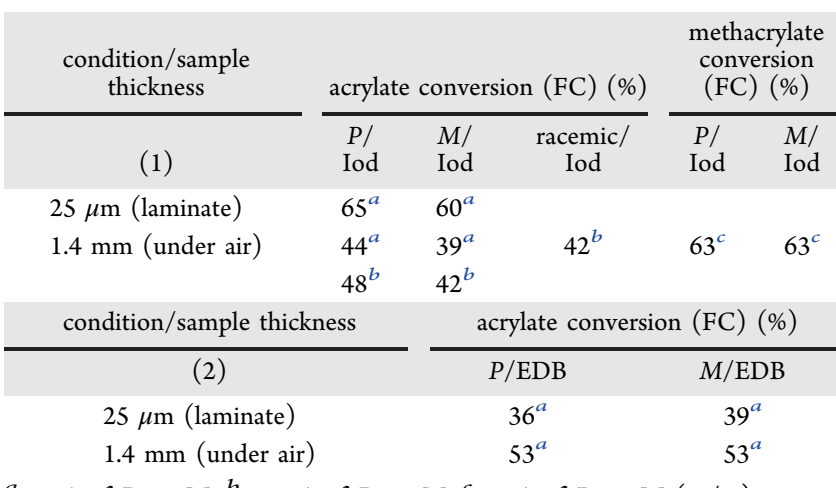

${ }^{a} 0.5 \%$ of $P$ or $M .{ }^{b} 0.25 \%$ of $P$ or $M .{ }^{c} 0.1 \%$ of $P$ or $M(\mathrm{w} / \mathrm{w})$.

Kinetics of thin samples $(25 \mu \mathrm{m})$ vs thick samples $(1.4 \mathrm{~mm})$ of acrylates: High FCs are reached in both $\mathrm{M} / \mathrm{EDB}$ and $\mathrm{P} / \mathrm{EDB}$ systems (e.g., $\mathrm{M} / \mathrm{EDB} \mathrm{FC}=39 \%$ and $\mathrm{P} / \mathrm{EDB} \mathrm{FC}=36 \%$ at $t=$ $100 \mathrm{~s}$ for the same concentration in TMPTA $(0.5 \% / 1.0 \%)$; Figure 6C, curves 1 and 2, respectively) for thin films. On the other hand, for thicker samples, higher FCs up to $53 \%$ for both $\mathrm{M} / \mathrm{EDB}$ curve 3 and $\mathrm{P} / \mathrm{EDB}(0.5 \% / 1.0 \%)$ curve 4 (Figure 6C) were obtained with LED@405 nm compared to the case of thin samples. This was expected, as kinetics are slower for thick samples at the beginning (intensity absorbed throughout the entire sample is more critical in thick samples compared to thin samples), but oxygen diffusion is less significant in thick samples, so higher FC can be obtained at the end for thicker samples.

Remarkably, the final color of the polymer using the $\mathrm{A} 6 \mathrm{H} /$ EDB system is pale yellow (not a very intense yellow color, unlike for $\mathrm{A} 6 \mathrm{H} / \mathrm{Iod})$. This indicates that different photoproducts are obtained in these systems.

Chiroptical Properties of the Polymer Films Obtained. Remarkably, when the enantiopure $\mathrm{A} 6 \mathrm{H}(M$ or $P) /$ Iod system is used to initiate the polymerization of acrylate monomer (TMPTA), the obtention of polymer films exhibiting chiroptical properties is clearly observed (Figure 7). The maximum chiroptical activity is observed in the 380-

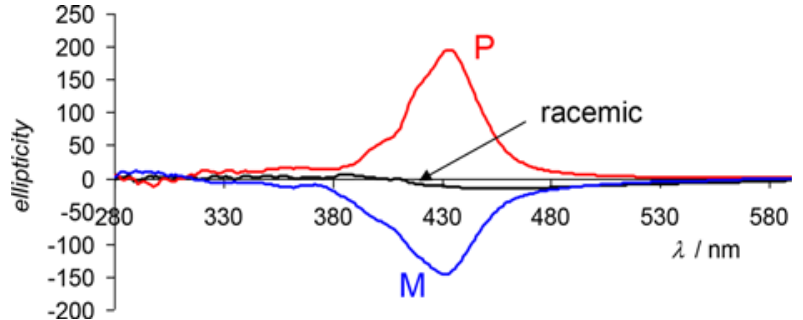

Figure 7. Ellipticity measurements of $1.4 \mathrm{~mm}$ polymer films obtained by photopolymerization of TMPTA under air using different photoinitiating systems: (P) (P)/Iod $(0.25 \% / 1 \%$ w/w) under LED@405 nm; (M) (M)/Iod (0.25\%/1\% w/w) under LED@405 $\mathrm{nm}$ and for the racemic $\mathrm{A} 6 \mathrm{H} / \operatorname{Iod}(0.25 \% / 1 \% \mathrm{w} / \mathrm{w})$. Ellipticity and $\mathrm{CD}$ are proportionally related according to $[\varphi] \sim 3300 \Delta \varepsilon$, where the brackets represent molar units.

$480 \mathrm{~nm}$ range with ellipticity values as high as 200 in $1.4 \mathrm{~mm}$ thin films. This circular dichroic response reveals very different from the enantiopure photoinitiator $\mathrm{A} 6 \mathrm{H}$ and appears positive for $\mathrm{P}-\mathrm{A} 6 \mathrm{H}$ and negative for $\mathrm{M}-\mathrm{A} 6 \mathrm{H}$. Furthermore, when using the racemic form rac-A6H, such properties were obviously not observed (Figure 7). The introduction of such chiroptical activity for methacrylic polymer films obtained from the polymerization of BisGMA/TEGDMA can be similarly observed (Figure 8). Note also that these results appeared reproducible; indeed, the imprinted chirality of the films increased with higher percentages of chiral photoinitiator up to saturation (see Figure S1). Indeed, at low loading of chiral initiator for the $\mathrm{A} 6 \mathrm{H} / \mathrm{Iod}$ system (0.15\%, Figure S1), the resulting polymer exhibits a complex mirror-image ECD signature presumably composed of a contribution from the chiral helicene initiator (for instance, positive band at $330 \mathrm{~nm}$ for $P-\mathrm{A} 6 \mathrm{H})$ or a molecular analogue, along with a broad intense response until $450 \mathrm{~nm}$, tentatively assigned to the polymeric material. Upon increasing the helicene loading from 0.15 to $0.75 \%$, the resulting ECD spectra evolves to a unique intense ECD band in the visible region attributed to the final polymeric material signature $(430 \mathrm{~nm}$, Figure S1). Because of the continuous red-shift and intensity increase of the latter, the characteristic ECD signature of the helicene initiator is no longer visible at higher energy, in line with the formation of a new multidimensional chiral network (vide infra).

Proposed Origin of the Intense Chiroptical Activity of the Polymer Film. It was observed that $\mathrm{A} 6 \mathrm{H}$ do not react during amine/benzoyl peroxide redox polymerization (see Figure S2). Therefore, using this amine/benzoyl peroxide redox initiating system that does not require light, polymer films with in situ embedded A6H were prepared (Figure S3). These films only exhibit a lower chiroptical activity in the $370-420 \mathrm{~nm}$ region which can be related to the chiroptical properties of trapped $\mathrm{A} 6 \mathrm{H}$ inside the polymer network. Using $P$ - or $M-\mathrm{A} 6 \mathrm{H}$ in the photoinitiating system, the maximum chiroptical activity becomes monosignate and more than 100 $\mathrm{nm}$ shifted to longer wavelength compared to in situ embedded $\mathrm{A} 6 \mathrm{H}$, strongly suggesting that the observed chiroptical activity is ascribed to a photochemical reaction of $\mathrm{A} 6 \mathrm{H}$ and/or to the newly formed chirally imprinted polymer. It was already shown by Okamoto and co-workers ${ }^{21-23}$ that "optically active polymers having helical conformation from bulky methacrylates" can be synthesized by either anionic or radical asymmetric polymerization processes. These polymers 

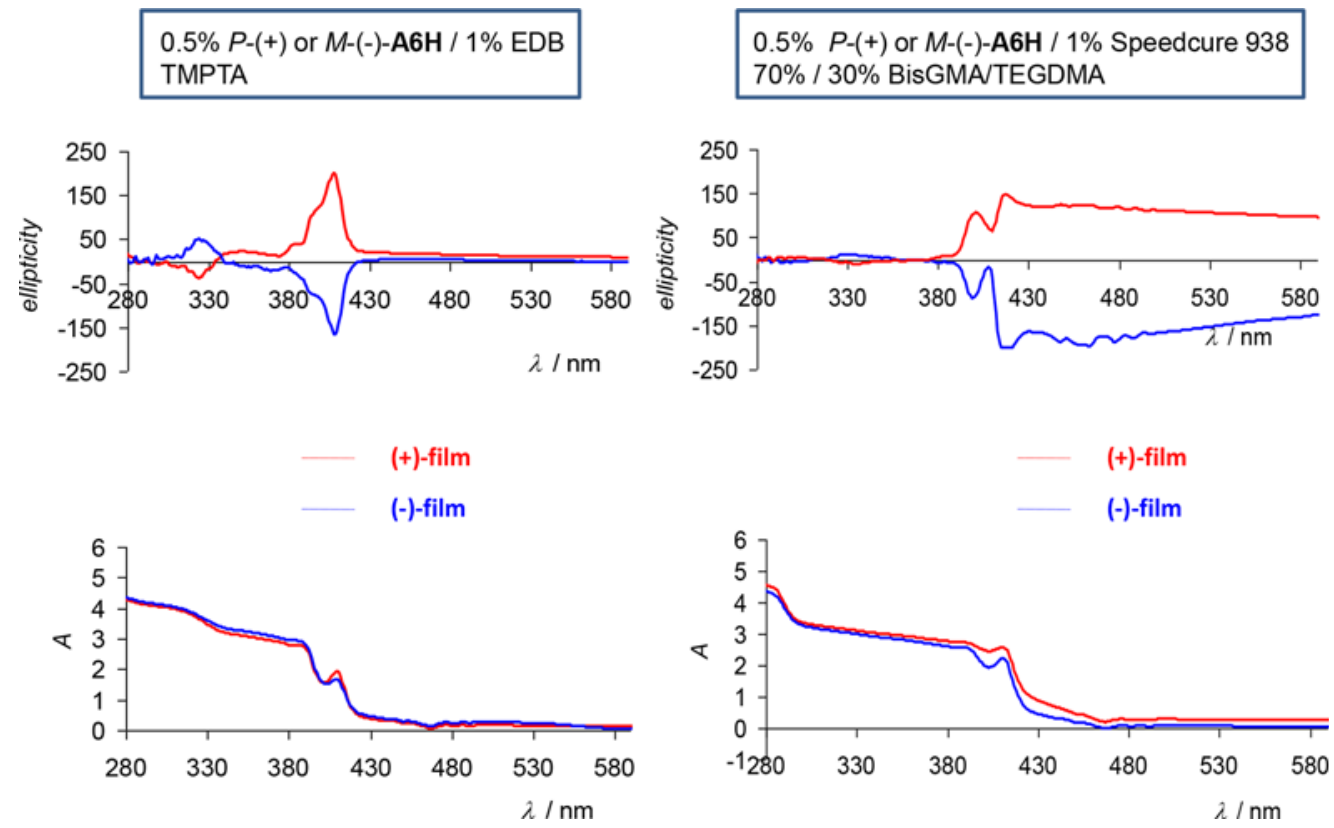

Figure 8. Ellipticity and absorbance measurements of $(+)$ (from $P-(+)-\mathrm{A} 6 \mathrm{H})$ and $(-)$ (from $M-(-)-\mathrm{A} 6 \mathrm{H})$ polymers films obtained under two different photopolymerization conditions.

Table 3. HR-ESI-MS Data and Structural Interpretation for Photolysis Experiments (under LED@405 nm) in DCM: (100 g/L $\mathrm{A} 6 \mathrm{H}+1$ equiv of $\mathrm{Iod})$ and $(100 \mathrm{~g} / \mathrm{L} \mathrm{A6H}+1$ equiv of Iod +1 equiv of HEMA)

\begin{tabular}{|c|c|c|}
\hline Photolysis & $\begin{array}{c}\text { Detected } \\
\text { Experiment }\end{array}$ & $\mathrm{m} / \mathrm{z}$ (Da) \\
{$[\mathrm{M}+\mathrm{H}]^{+}$} & & Attribution* \\
\hline A6H/Iod & $\mathrm{C}_{36} \mathrm{H}_{30} \mathrm{~N}^{+}$ & $-1.6 \mathrm{ppm}$ \\
\hline $\mathrm{A6H/Iod} / \mathrm{HEMA}$ & $\mathrm{C}_{36} \mathrm{H}_{30} \mathrm{~N}^{+}$ & 476.2371 \\
& & $-0.4 \mathrm{ppm}$ \\
\hline
\end{tabular}

*The new proposed photoproduct.

indeed exhibited "main chain chirality". We propose that we are in a similar situation for our chiral 3D polymeric films.

To better understand the possible reason behind the strong chiroptical activity in the obtained polymer synthesized by photopolymerization, we used HR-ESI-MS to determine the nature of a possible $\mathrm{A} 6 \mathrm{H} / \mathrm{Iod}$ photoproduct. Surprisingly, no A6H/HEMA adduct is observed (should be noted at 476.2215 Da, see Table 3) (HEMA is used as a pure monomer). This would have explained an intramolecular transfer of chirality from the helicene to the polymer chain as what is presented in the literature. ${ }^{21}$ On the contrary, in the present case, the same photoproduct is observed in the case of either $\mathrm{A} 6 \mathrm{H} / \mathrm{Iod}$ photolysis or A6H/Iod/HEMA photolysis and corresponds to the structure presented in Table 3. Considering the broad chiroptical activity observed which appears shifted to longer wavelengths and strongly different from the starting $\mathrm{A} 6 \mathrm{H}$ (monosignate instead of bisignate), it can be suggested that the tert-butyl aryl radical reacted with the chiral $\mathrm{A} 6 \mathrm{H}$ radical cation (both species generated in the $\mathrm{A} 6 \mathrm{H} / \mathrm{Iod}$ photochemical interaction in reaction $\mathrm{r} 2$; the position of the addition is not determined), which in its turn induces a stable chiral conformational to the whole helical polymer in the solid 

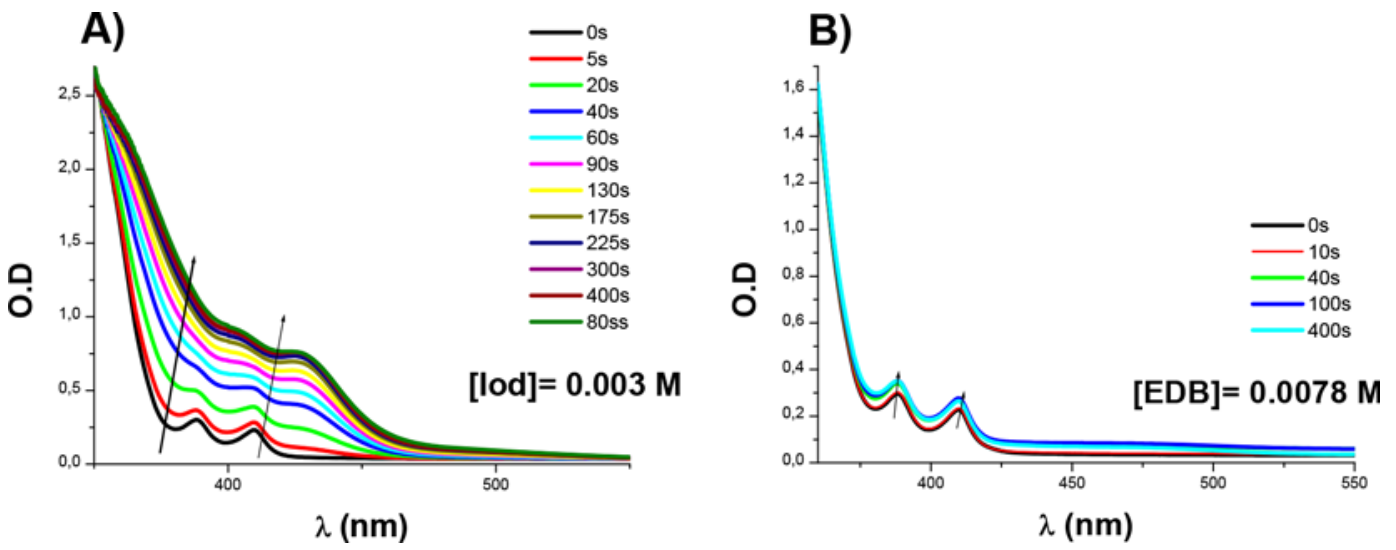

Figure 9. (A) M/Iod photolysis upon exposure with LED@405 nm. (B) M/EDB photolysis upon exposure with LED@405 nm.

state. ${ }^{22}$ In addition, it is consistent with the UV-vis absorption range $(380-600 \mathrm{~nm})$ which fits with the ellipticity responses (Figure 7); indeed, this UV-vis absorption evolution (from a photoproduct) was observed explicitly during $\mathrm{A} 6 \mathrm{H} / \mathrm{Iod}$ photolysis experiments (Figure 9A). This observation further suggests that the strong chiroptical response do originate from absorption phenomena and not from light scattering. Our analysis is also consistent with luminescence measurements of the films which show a broad emission centered at $500 \mathrm{~nm}$ (see Figure S4), which is different from the starting $\mathrm{A} 6 \mathrm{H}$ precursor (Figure 5A). Note, however, that attempts in measuring circularly polarized luminescence of these films were unsuccessful, probably due to the lack of homogeneity and to the anisotropy of the films. Overall, the enantiopure derivative inducing the chirality to the whole bulk material may be of different origins: it may be due to the precursor $\mathrm{A} 6 \mathrm{H}$ itself, to the suggested photoproduct detected by MS, or to any other related chiral species present in the system.

The imprinted chirality of the films is also ascertained by the ellipticity of different films obtained by different conditions, i.e., (i) when using $0.5 \% P-(+)$ or $M-(-)-\mathrm{A} 6 \mathrm{H} / 1 \% \mathrm{EDB}$ as photoinitiators with TMTPA as monomers and (ii) with $P-(+)$ or $M-(-)-\mathrm{A} 6 \mathrm{H} / 1 \%$ Speedcure 938 as photoinitiators and $70 \% / 30 \%$ BisGMA/TEGDMA as mixture of monomers (Figure 8). Note that in the latter case some additional chiral signature above $430 \mathrm{~nm}$ is appearing and is probably due to light scattering.

Chemical Mechanisms. Steady-State Photolysis. The steady-state photolysis of $\mathrm{A} 6 \mathrm{H} / \mathrm{Iod}$ solution in acetonitrile upon irradiation with a LED@405 nm is much faster than that of $\mathrm{A} 6 \mathrm{H}$ alone or $\mathrm{A} 6 \mathrm{H} / \mathrm{EDB}$ (e.g., M/Iod in Figure 9A vs M/ EDB alone in Figure 9B). A new photoproduct (characterized by a significant absorption for $\lambda>400 \mathrm{~nm}$ ) is formed due to the $\mathrm{A} 6 \mathrm{H} / \mathrm{Iod}$ interaction (see the HR-MS data above and the origin of the chirality).

Free Energy Change $\Delta G_{\text {et }}$ Fluorescence Quenching, and ESR Experiments. A triplet-triplet energy transfer between $\mathrm{A} 6 \mathrm{H}$ and Iod can be excluded. Such a photosensitization process is well-known but occurs with a sensitizer exhibiting a high-energy-lying triplet state $(\gg 75 \mathrm{kcal} / \mathrm{mol}){ }^{20}$ This is, for example, the case with acetone (triplet state energy $E_{\mathrm{T}}=80$ $\mathrm{kcal} / \mathrm{mol}){ }^{20}$ In the present case, the excited singlet state of $\mathrm{A} 6 \mathrm{H}$ is already lower than $75 \mathrm{kcal} / \mathrm{mol}$ (Table 1 ); therefore, its triplet state is also lower in energy rendering the occurrence of a triplet-triplet energy transfer totally excluded. In contrast, for the electron transfer between $\mathrm{A} 6 \mathrm{H}$ and Iod, both the formation of aryl radicals (generated from the reduction of iodonium salt) and favorable free energy change for the electron transfer reaction are observed $\left(\Delta G_{\mathrm{et}}\right)$.

The free energy change $\Delta G_{\text {et }}$ for the electron transfer reaction between $\mathrm{A} 6 \mathrm{H}$ and iodonium salt (Iod) (as electron acceptor) and EDB (as an electron donor) was calculated from the classical equation (eq 1$)^{18}$ using the $E_{\mathrm{ox}}, E_{\mathrm{red}}$, and the singlet excited state energy $E_{\mathrm{S} 1}$ of A6H. Finally, $\Delta G_{\text {et }}$ of the photo-oxidation by Iod and photoreduction by EDB is highly favorable for both enantiomers of $\mathrm{A} 6 \mathrm{H}$, i.e., $\sim-1.0 \mathrm{eV}$ for photooxidation, and slightly less favorable with $\sim 0.0 \mathrm{eV}$ for photoreduction (Table 4).

Table 4. Parameters Characterizing the Chemical Mechanisms Associated with $\mathrm{A} 6 \mathrm{H} / \mathrm{Iod}$ or $\mathrm{A6H} / \mathrm{EDB}$ in Acetonitrile

\begin{tabular}{ccccccc} 
& \multicolumn{3}{c}{${ }^{1} \mathrm{~A} 6 \mathrm{H} / \mathrm{Iod}$} & & \multicolumn{2}{c}{${ }^{1} \mathrm{~A} 6 \mathrm{H} / \mathrm{EDB}$} \\
\cline { 2 - 4 } \cline { 6 - 7 } A6H & $K_{\mathrm{sv}}{ }^{a}\left(\mathrm{M}^{-1}\right)$ & $\Phi_{\mathrm{et}}{ }^{a}$ & $\Delta G_{\mathrm{et}}{ }^{a}(\mathrm{eV})$ & & $\Phi_{\mathrm{et}}{ }^{b}$ & $\Delta G_{\mathrm{et}}{ }^{b}(\mathrm{eV})$ \\
$P$ & 362 & 0.87 & -1.0 & & 0.99 & 0.0 \\
$M$ & 244 & 0.82 & -1.0 & & 0.99 & 0.0
\end{tabular}

${ }^{a}$ Calculated from the free energy change equation (eq 1) using $E_{\text {red(Iod) }}=-0.6 \mathrm{eV}^{20,24}{ }^{b}$ Calculated from the free energy change equation (eq 1) using $E_{\mathrm{ox}(\mathrm{EDB})}=1.1 \mathrm{e} . \mathrm{V}^{20,24}$

Fluorescence experiments for $\mathrm{A} 6 \mathrm{H}$ were carried out in acetonitrile (Table 4). Favorable fluorescence quenching processes were evidenced by higher value of the SternVolmer coefficients for ${ }^{1} \mathrm{~A} 6 \mathrm{H} / \mathrm{EDB}$ vs ${ }^{1} \mathrm{~A} 6 \mathrm{H} / \mathrm{Iod}$ processes $\left(K_{\text {sv }}\right.$; Figure 10 and Table 4$)$ and very high electron transfer quantum yields $\left(\Phi_{\mathrm{et}}\right)$ (calculated according to reaction $\mathrm{r} 1{ }^{20}$ Table 4) for both ${ }^{1} \mathrm{~A} 6 \mathrm{H} / \mathrm{EDB}$ and ${ }^{1} \mathrm{~A} 6 \mathrm{H} / \mathrm{Iod}$ (e.g., for ${ }^{1} \mathrm{~A} 6 \mathrm{H}$ $/ \mathrm{EDB} \Phi_{\mathrm{et}}=0.99$ and for ${ }^{1} \mathrm{~A} 6 \mathrm{H} / \mathrm{Iod} \Phi_{\mathrm{et}}=0.82$; see Table 4). The very high $\Phi_{\text {et }}$ cannot discriminate the reactivity with EDB or Iod as well as the initiating ability (see above Iod $\gg$ EDB) strongly suggesting that back electron transfer in the case of ${ }^{1} \mathrm{~A} 6 \mathrm{H} / \mathrm{EDB}$ might have taken place (supported by low photolysis observed for the A6H/EDB system).

$$
\Phi_{\text {et }}=K_{\text {sv }} \text { [quencher] } /\left(1+K_{\text {sv }} \text { [quencher] }\right)
$$

The favorable quenching process of $\mathrm{A} 6 \mathrm{H}$ as a photoinitiator (PI) by Iod is schematized with the reactions $\mathrm{r} 2$ and confirmed by our ESR results. Typical hyperfine couplings constants for the spin trapping radical adducts using $\operatorname{PBN}\left(a_{\mathrm{N}}=14.06\right.$ and $a_{\mathrm{H}}=2.12$ ) correspond to the aryl radical (e.g., racemic/Iod, Figure 11). 


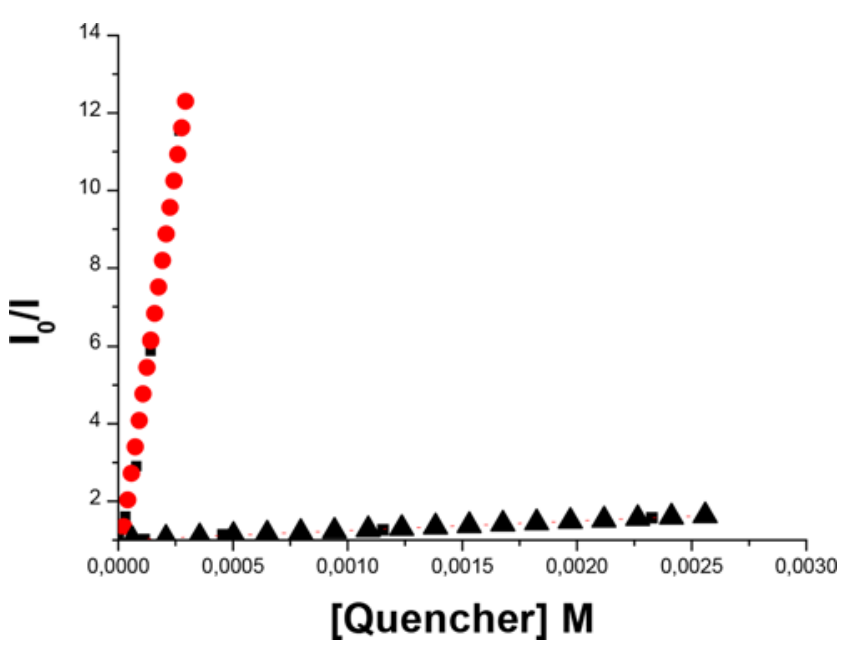

Figure 10. Stern-Volmer treatment for the $(\boldsymbol{\Delta}) \mathrm{M} / \mathrm{Iod}$ and $(\mathbf{O}) \mathrm{M} /$ EDB.

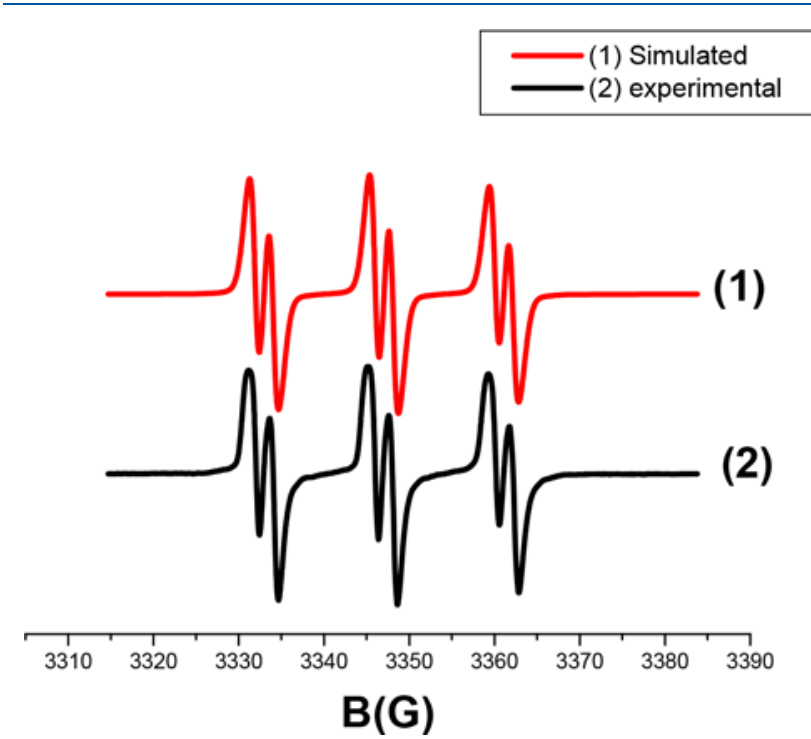

Figure 11. ESR-ST spectra obtained upon irradiation (LED@405 $\mathrm{nm}$ ) of $\mathrm{A} 6 \mathrm{H} / \mathrm{Iod}$ : experimental (lower spectrum) and simulated (upper spectrum) in tert-butylbenzene.

\section{CONCLUSION}

In the present paper, aza[6]helicene enantiomers characterized by high visible light absorptions were investigated as chiral photoinitiators/photosensitizers for radical reactions upon violet LEDs. Remarkably, enantiopure aza[6]helicene (A6H) acts as a dual functional system. On the one hand, it acts as high-performance photoinitiator in both photooxidative and photoreductive processes. On the other hand, it transfers the chirality to the synthesized polymers: this can be useful for applications utilizing circularly polarized light (CPL). To the best of our knowledge, this is the first example of chiroptical properties introduced in polymer films by the photoinitiator through photopolymerization processes. Other photoinitiating systems generating chiroptical properties will be investigated in forthcoming papers.

\section{ACKNOWLEDGMENTS}

The Lebanese group thanks "The Association of Specialization and Scientific Guidance" (Beirut, Lebanon) for funding and supporting this scientific work. J.O. thanks the Chinese Scientific Council for financial support. L.F. and J.C. thank Prof. Lorenzo Di Bari from University of Pisa for tentative circularly polarized emission measurements.

(1) Watson, J. D.; Crick, F. H. The Structure of DNA. In Cold Spring Harbor Symposia on Quantitative Biology; Cold Spring Harbor Laboratory Press:1953; Vol. 18, pp 123-131.

(2) Shen, Y.; Chen, C.-F. Helicenes: Synthesis and Applications. Chem. Rev. 2012, 112, 1463-1535.

(3) Chen, C.-F.; Shen, Y. Helicene Chemistry: From Synthesis to Applications; Springer: 2016.

(4) Gingras, M. One hundred years of helicene chemistry. Part 3: applications and properties of carbohelicenes. Chem. Soc. Rev. 2013, 42, 1051-1095.

(5) Bosson, J.; Gouin, J.; Lacour, J. Cationic triangulenes and helicenes: synthesis, chemical stability, optical properties and extended applications of these unusual dyes. Chem. Soc. Rev. 2014, 43, 2824-2840.

(6) Narcis, M. J.; Takenaka, N. Helical-Chiral Small Molecules in Asymmetric Catalysis. Eur. J. Org. Chem. 2014, 21-34.

(7) Aillard, P.; Voituriez, A.; Marinetti, A. Dalton Trans. 2014, 43, 15263-15278.

(8) Saleh, N.; Shen, C.; Crassous, J. Helicene-based transition metal complexes: synthesis, properties and applications. Chem. Sci. 2014, 5, 3680-3694.

(9) Newman, M. S.; Lednicer, D. The Synthesis and Resolution of Hexahelicene. J. Am. Chem. Soc. 1956, 78, 4765-4770.

(10) Nakano, K.; Oyama, H.; Nishimura, Y.; Nakasako, S.; Nozaki, K. $\lambda^{5}$-Phospha[7]helicenes: Synthesis, Properties, and Columnar Aggregation with One-Way Chirality. Angew. Chem. 2012, 124, 719-723. 
(11) Al Mousawi, A.; Dumur, F.; Garra, P.; Toufaily, J.; Hamieh, T.; Goubard, F.; Bui, T.-T.; Graff, B.; Gigmes, D.; Fouassier, J.-P.; Lalevée, J. Azahelicenes as Visible Light Photoinitiators for Cationic and Radical Polymerization: Preparation of Photoluminescent Polymers and Use in High Performance LED Projector 3D Printing Resins. J. Polym. Sci., Part A: Polym. Chem. 2017, 55, 1189-1199.

(12) Harada, Y.; Sakajiri, K.; Kuwahara, H.; Kang, S.; Watanabe, J.; Tokita, M. Cholesteric films exhibiting expanded or split reflection bands prepared by atmospheric photopolymerisation of diacrylic nematic monomer doped with a photoresponsive chiral dopant. $J$. Mater. Chem. C 2015, 3, 3790-3795.

(13) Kumar, K.; Schenning, A. P.; Broer, D. J.; Liu, D. Regulating the modulus of a chiral liquid crystal polymer network by light. Soft Matter 2016, 12, 3196-3201.

(14) Okamoto, Y. Chiral polymers for resolution of enantiomers. J. Polym. Sci., Part A: Polym. Chem. 2009, 47, 1731-1739.

(15) Foresman, J. B.; Frisch, A. Exploring Chemistry with Electronic Structure Methods, 2nd ed.; Gaussian Inc.: Pittsburgh, PA, 1996.

(16) Frisch, M. J.; Trucks, G. W.; Schlegel, H. B.; Scuseria, G. E.; Robb, M. A.; Cheeseman, J. R.; Zakrzewski, V. G.; Montgomery, J. A.; Stratmann, J. R. E.; Burant, J. C.; Dapprich, S.; Millam, J. M.; Daniels, A. D.; Kudin, K. N.; Strain, M. C.; Farkas, O.; Tomasi, J.; Barone, V.; Cossi, M.; Cammi, R.; Mennucci, B.; Pomelli, C.; Adamo, C.; Clifford, S.; Ochterski, J.; Petersson, G. A.; Ayala, P. Y.; Cui, Q.; Morokuma, K.; Salvador, P.; Dannenberg, J. J.; Malick, D. K.; Rabuck, A. D.; Raghavachari, K.; Foresman, J. B.; Cioslowski, J.; Ortiz, J. V.; Baboul, A. G.; Stefanov, B. B.; Liu, G.; Liashenko, A.; Piskorz, P.; Komaromi, I.; Gomperts, R.; Martin, R. L.; Fox, D. J.; Keith, T.; Al-Laham, M. A.; Peng, C. Y.; Nanayakkara, A.; Challacombe, M.; Gill, P. M. W.; Johnson, B.; Chen, W.; M. Wong, W.; Andres, J. L.; Gonzalez, C.; Head-Gordon, M.; Replogle, E. S.; Pople, J. A. Gaussian 03, Revision B-2; Gaussian, Inc.: Pittsburgh, PA, 2003.

(17) Lalevée, J.; Blanchard, N.; Tehfe, M. A.; Morlet-Savary, F.; Fouassier, J. P. Green Bulb Light Source Induced Epoxy Cationic Polymerization under Air Using Tris(2,2'-bipyridine)ruthenium(II) and Silyl Radicals. Macromolecules 2010, 43, 10191-10195.

(18) Rehm, D.; Weller, A. Kinetics of Fluorescence Quenching by Electron and H-Atom Transfer. Isr. J. Chem. 1970, 8, 259-271.

(19) Lalevée, J.; Blanchard, N.; Tehfe, M.-A.; Peter, M.; MorletSavary, F.; Gigmes, D.; Fouassier, J.-P. Efficient Dual Radical/ Cationic Photoinitiator under Visible Light: A New Concept. Polym. Chem. 2011, 2, 1986-1991.

(20) Fouassier, J.-P.; Lalevée, J. Photoinitiators for Polymer Synthesis: Scope, Reactivity, and Efficiency; John Wiley \& Sons: 2012.

(21) Nakano, T.; Okamoto, Y. Asymmetric polymerization of methacrylates. Macromol. Rapid Commun. 2000, 21, 603-612.

(22) Nakano, T.; Okamoto, Y. Synthetic Helical Polymers: Conformation and Function. Chem. Rev. 2001, 101, 4013-4038.

(23) Wulff, G. Main-Chain Chirality and Optical Activity in Polymers Consisting of C-C Chains. Angew. Chem., Int. Ed. Engl. 1989, 28, 21-37.

(24) Strehmel, B. In Dyes and Chomophores in Polymer Science; Lalevée, J., Fouassier, J.-P., Eds.; John Wiley \& Sons: London, 2015. 